\author{
Stefan Jenisch • Jochen Hampe $\cdot$ James T. Elder \\ Rajan Nair · Phil Stuart · John J. Voorhees \\ Stefan Schreiber • Dietrich Kabelitz \\ Enno Christophers • Michael Weichenthal
}

\title{
CARD15 mutations in patients with plaque-type psoriasis and psoriatic arthritis: lack of association
}

Received: 1 June 2005/ Revised: 26 October 2005/ Accepted: 1 November 2005/Published online: 10 January 2006

(C) Springer-Verlag 2006

\begin{abstract}
Psoriasis has a strong genetic component in the development of the disease as indicated by familial occurrence and a high concordance rate among monozygotic twins. In genome-wide scans for psoriasis several susceptibility loci have been detected, but the diseasecausing genes have not yet been identified. A recent scan, performed on psoriatic arthritis (PsA), which occurs in about $15 \%$ of the psoriasis patients showed a significant locus on chromosome 16 in a region that was already described by genome scan for psoriasis. CARD15, a major susceptibility gene for Crohn's disease (CD) on chromosome $16 \mathrm{q}$, is an interesting candidate gene for psoriasis, because there is a documented clinical association of $\mathrm{CD}$ with psoriasis, and recently the association of CARD15 mutations with PsA was reported in Newfoundland population. We investigated the association of this variant with PsA and the overall psoriasis genotype in 59 independent patients with PsA in comparison with 361 age and sex-matched controls. In addition, a second cohort of 89 independent North American PsA
\end{abstract}

S. Jenisch $(\varangle) \cdot$ D. Kabelitz

Department of Immunology, University of Kiel, Michaelisstr. 5, 24105 Kiel, Germany

E-mail: jenisch@immunologie.uni-kiel.de

Tel.: + 49-431-5973380

Fax: + 49-431-5971606

J. Hampe $\cdot$ S. Schreiber

Department of Internal Medicine, University of Kiel,

Kiel, Germany

J. T. Elder $\cdot$ R. Nair $\cdot$ P. Stuart · J. J. Voorhees

Department of Dermatology, University of Michigan,

Ann Arbor, MI, USA

\section{J. T. Elder}

Department of Radiation Oncology (Cancer Biology), University of Michigan, Ann Arbor, MI, USA

\section{J. T. Elder}

Ann Arbor Veterans Affairs Hospital, Ann Arbor, MI, USA

E. Christophers · M. Weichenthal

Department of Dermatology, University of Kiel, Kiel, Germany patients was included. The diagnosis of psoriasis was made by a dermatologist based on standard clinical criteria. In these patients, PsA was defined as an inflammatory joint disease, negative rheumatoid factor, and lack of another causative condition for arthritis. Using case-control analysis, the G908R mutation was weakly associated with psoriasis and PsA, but due to the low frequency of this mutation statistical significance was not reached. All other variants including leu1007fsinsC and R702W did not show any association with psoriasis or PsA. In conclusion, a disease-causing role for CARD15 mutations could not be confirmed in German or American subjects with PsA.

Psoriasis is a chronic inflammatory skin disorder of unknown etiology affecting around $2 \%$ of the general population in the US and Europe. There is a strong genetic component in the development of the disease as indicated by familial occurrence and a high concordance rate among monozygotic twins [4]. In a genome-wide scan for psoriasis susceptibility loci, a putative susceptibility region was detected on chromosome 16q [12]. A recent scan, performed on psoriatic arthritis, which occurs in about $15 \%$ of the patients with plaque-type psoriasis, confirmed a significant locus in that region [8].

CARD15, a major susceptibility gene for Crohn's disease (CD) on chromosome 16q, is an interesting candidate gene for psoriasis, because there is a documented clinical association of $\mathrm{CD}$ with psoriasis [10]. Previous investigations of one or more of the major CDassociated $C A R D 15$ variants in patients with psoriasis did not reveal any significant association [2, 13]. Recently, Rahman et al. reported on the association of CARD15 mutations with PsA [14]. As the principal finding, association of $\mathrm{R} 702 \mathrm{~W}$ was highly significant with an odds ratio of 3.50 .

We investigated association of this variant with PsA in patients from our collaborative cohort of more than 
Table 1 Genotypes of $C A R D 15$ variants in patients with psoriatic arthritis

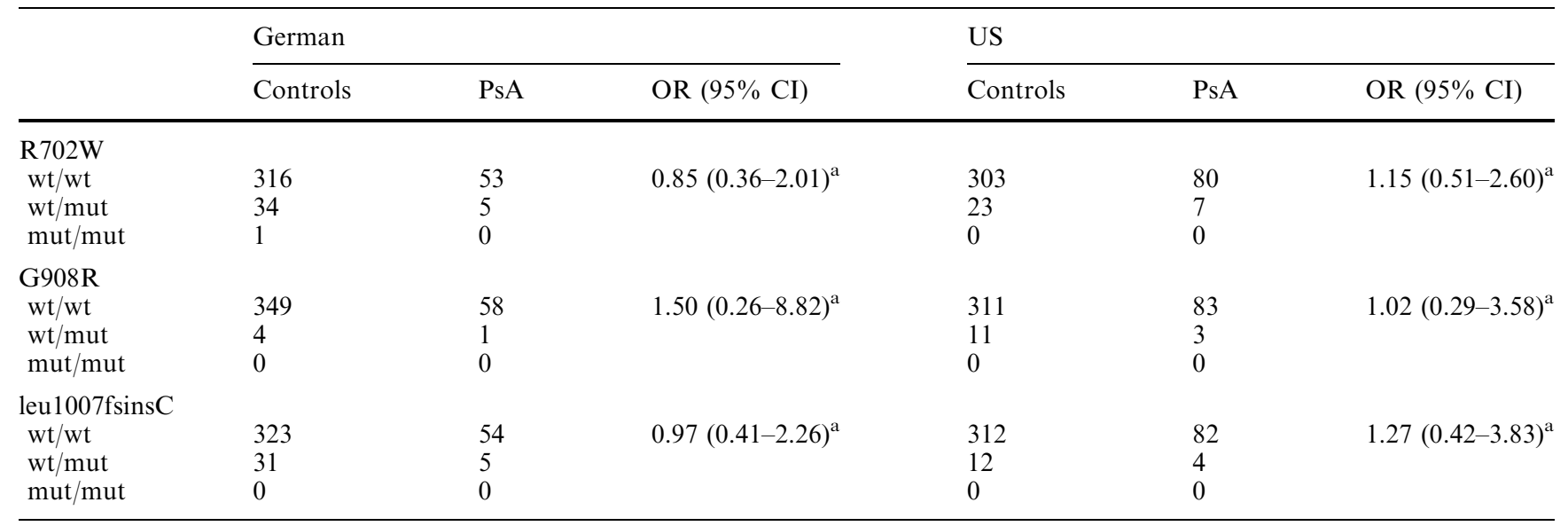

PsA psoriatic arthritis subset $(n=146)$ of psoriasis patients compared with healthy controls $(n=686)$ in a German and an American cohort; missing values are due to technical errors. $O R$ odds ratios are based on the presence of at least one mutated allele versus none, 95\% CI: 95\% confidence intervals, wt wild type, mut mutated allele

${ }^{a} P>0.05$ after adjustment for multiple testing

800 independent cases with plaque-type psoriasis in comparison with age and sex-matched controls. From the German cohort, 59 unequivocal PsA cases could be identified, 89 independent PsA patients were included from the North American cohort. The diagnosis of psoriasis was made by a dermatologist based on standard clinical criteria. In these patients, PsA was defined as an inflammatory joint disease, negative rheumatoid factor, and lack of another causative condition for arthritis. Appropriate control populations from Germany and North America, respectively, were sampled from local blood donor services. All probands were found to be free of relevant diseases by history, physical examination, and standard laboratory testing.

CARD15 variants were genotyped as described [7] and data were curated in an integrated database [6].

For the whole study population, no significant association of psoriasis with CARD15 mutations was found (data not shown). As indicated in Table 1, in the two subset of patients with PsA none of the three mutations tested showed a significant association with the disease. Combined odds ratios for the whole PsA study population were also lacking any significant association (Table 2). While the number of PsA patients in our cohort is substantially lower than in the study done by Rahman et al., our subset of patients with PsA still has a

Table 2 Common odds ratio for CARD15 variants

\begin{tabular}{lll}
\hline Variant & OR & $95 \% \mathrm{CI}$ \\
\hline R702W & 1.00 & $0.52-1.92$ \\
G908R & 1.12 & $0.37-3.43$ \\
leu1007fsinsC & 1.08 & $0.51-2.28$ \\
\hline
\end{tabular}

$O R$ common odds ratios (Mantel-Haenszel) calculated for the combined subset of German and American PsA patients are based on the presence of at least one mutated allele versus none; $95 \% \mathrm{CI}$ : $95 \%$ confidence intervals power of $80 \%$ to detect an odds ratio of at least 2.1 with an observed frequency of the R702W mutation in controls of $10 \%$ and a significance level of 0.05 [3]. The G908R mutation was weakly associated with psoriasis and PsA, but due to the low frequency of this mutation statistical significance was not reached. Interestingly, the leu1007fsinsC mutation was less frequent in our psoriasis cohort than in the control population, although not statistically significant after correction for multiple comparisons. In summary, the reported effect of R702W on PsA could not be reproduced in this sample of German and American psoriasis patients.

As the allele frequency of the $\mathrm{R} 702 \mathrm{~W}$ variant in the control populations of both studies is very similar, the reported effect of Rahman et al. may either be population-specific or may be the result of LD to some as yet unidentified variant in the CARD15 gene or its genomic neighborhood. Moreover, the Newfoundland population is a relatively isolated one, in which several founder effects have been identified $[15,16]$. While the R702W allele seems too common to be the source of a founder effect, it is possible that such an effect is present in a gene with which $C A R D 15$ interacts. Alternatively, selection bias may partly explain the divergent results. Clinical assessment of PsA is a critical issue, as a specific diagnostic test is not available. There are several clinical phenotypes in PsA [11] and the published prevalence of PsA in psoriasis patients varies between 7 and $30 \%$ [17]. PsA patients attending a rheumatologic department can be expected to be more severely affected than patients recruited from a psoriasis population. Accordingly, Rahman et al. (2003) noted that patients carrying the R702W mutation had a tendency towards an increased rate of corticosteroid medication and joint surgery, reflecting pronounced disease severity.

In conclusion, our results fail to confirm an effect of CARD 15 variants in PsA. This is in accordance with very recent reports from both an Italian and from a Germany 
cohort also lacking any significant association of $C A R D 15$ variants in PsA [5, 9]. However, the confirmation of chromosome $16 \mathrm{q}$ as a putative susceptibility locus for psoriasis [1] supports further analysis of this region.

Acknowledgements The study was conducted according to the Declaration of Helsinki Principles and approved by the medical ethical committee of the University of Kiel. This work was supported by a German National Genome Research Network Grant (BMFT 01 GS 0171 and BMBF NUW-S23T10).

\section{References}

1. Anonymous (2003) The International Psoriasis Genetics Study: assessing linkage to 14 candidate susceptibility loci in a cohort of 942 affected sib pairs. Am J Hum Genet 73(2):430-437

2. Borgiani P, Vallo L, D'Apice MR, Giardina E, Pucci S, Capon F, Nistico S, Chimenti S, Pallone F, Novelli G (2002) Exclusion of CARD15/NOD2 as a candidate susceptibility gene to psoriasis in the Italian population. Eur $\mathbf{J}$ Dermatol 12(6):540-542

3. Dupont WD, Plummer WD Jr (1990) Power and sample size calculations. A review and computer program. Control Clin Trials 11(2):116-128

4. Elder JT, Nair RP, Henseler T, Jenisch S, Stuart P, Chia N, Christophers E, Voorhees JJ (2001) The genetics of psoriasis 2001: the odyssey continues. Arch Dermatol 137(11):1447-1454

5. Giardina E, Novelli G, Costanzo A, Nistico S, Bulli C, Sinibaldi C, Sorgi ML, Chimenti S, Pallone F, Taccari E, Borgiani P (2004) Psoriatic arthritis and CARD15 gene polymorphisms: no evidence for association in the italian population. J Invest Dermatol 122(5):1106-1107

6. Hampe J, Wollstein A, Lu T, Frevel HJ, Will M, Manaster C, Schreiber S (2001) An integrated system for high throughput TaqMan based SNP genotyping. Bioinformatics 17(7): 654-655

7. Hampe J, Grebe J, Nikolaus S, Solberg C, Croucher PJ, Mascheretti S, Jahnsen J, Moum B, Klump B, Krawczak M, Mirza MM, Foelsch UR, Vatn M, Schreiber S (2002) Association of NOD2 (CARD 15) genotype with clinical course of Crohn's disease: a cohort study. Lancet 359(9318):1661-1665
8. Karason A, Gudjonsson JE, Upmanyu R, Antonsdottir AA, Hauksson VB, Runasdottir EH, Jonsson HH, Gudbjartsson DF, Frigge ML, Kong A, Stefansson K, Valdimarsson $\mathrm{H}$, Gulcher JR (2003) A susceptibility gene for psoriatic arthritis maps to chromosome 16q: evidence for imprinting. Am J Hum Genet 72(1):125-131

9. Lascorz J, Burkhardt H, Huffmeier U, Bohm B, SchurmeyerHorst F, Lohmann J, Stander M, Wendler J, Kelsch R, Baumann C, Kuster W, Traupe H, Reis A (2005) Lack of genetic association of the three more common polymorphisms of CARD15 with psoriatic arthritis and psoriasis in a German cohort. Ann Rheum Dis 64(6):951-954

10. Lee FI, Bellary SV, Francis C (1990) Increased occurrence of psoriasis in patients with Crohn's disease and their relatives. Am J Gastroenterol 85:962-963

11. Moll JM, Wright V (1973) Psoriatic arthritis. Semin Arthritis Rheum 3(1):55-78

12. Nair RP, Henseler T, Jenisch S, Stuart P, Bichakjian CK, Lenk W, Westphal E, Guo SW, Christophers E, Voorhees JJ, Elder JT (1997) Evidence for two psoriasis susceptibility loci (HLA and $17 q)$ and two novel candidate regions (16q and 20p) by genome-wide scan. Hum Mol Genet 6(8):1349-1356

13. Nair RP, Stuart P, Ogura Y, Inohara N, Chia NV, Young L, Henseler T, Jenisch S, Christophers E, Voorhees JJ, Nunez G, Elder JT (2001) Lack of association between NOD2 3020InsC frameshift mutation and psoriasis. $\mathbf{J}$ Invest Dermatol 117(6):1671-1672

14. Rahman P, Bartlett S, Siannis F, Pellett FJ, Farewell VT, Peddle L, Schentag CT, Alderdice CA, Hamilton S, Khraishi M, Tobin Y, Hefferton D, Gladman DD (2003) CARD15: a pleiotropic autoimmune gene that confers susceptibility to psoriatic arthritis. Am J Hum Genet 73(3):677-681

15. Spirio L, Green J, Robertson J, Robertson M, Otterud B, Sheldon J, Howse E, Green R, Groden J, White R, Leppert M (1999) The identical $5^{\prime}$ splice-site acceptor mutation in five attenuated APC families from Newfoundland demonstrates a founder effect. Hum Genet 105(5):388-398

16. Young TL, Woods MO, Parfrey PS, Green JS, Hefferton D, Davidson WS (1999) A founder effect in the newfoundland population reduces the Bardet-Biedl syndrome I (BBS1) interval to $1 \mathrm{cM}$. Am J Hum Genet 65(6):1680-1687

17. Zachariae H (2003) Prevalence of joint disease in patients with psoriasis: implications for therapy. Am J Clin Dermatol $4(7): 441-447$ 